\title{
Modelling Interdependencies in an Electrical Motor Manufacturing Process Involving Deformable Material
}

\author{
Izhar Oswaldo ESCUDERO-ORNELAS ${ }^{\text {a }}$, Divya TIWARI ${ }^{\mathrm{a}}$, Michael FARNSWORTH ${ }^{\mathrm{a}}$ \\ and Ashutosh TIWARI ${ }^{\mathrm{a}}$ \\ a Department of Automatic Control and Systems Engineering (ACSE), University of \\ Sheffield, Sheffield, UK
}

\begin{abstract}
Electrical machines have recently received a lot of attention due to a variety of applications in several industries. Although advances in digital technologies have enabled more efficient production of electrical machines, faults are still identified at the end of the line tests. In order to avoid accumulation of defects during the production chain, it is desirable to identify faults early in the process. This can be achieved by identifying how critical process parameters and the interdependencies between them influence the occurrence of faults. This poses a challenge in electrical machine manufacturing because of the complexity involved in various manufacturing steps involving deformable material, an example is coil winding.

This paper proposes a computational framework to model interdependencies in a complex electrical machine manufacturing process involving deformable material. A Discrete Event Simulation model representing the coil winding process demonstrated that input parameters such as wire tension and winding speed influence physical and electrical properties of the coil (enamelled copper wire) leading to generation of defects in the final product.
\end{abstract}

Keywords. Modelling, Interdependencies, Discrete Event Simulation, Coil Winding

\section{Introduction}

The global shift towards reducing carbon emissions has resulted in significant interest in electrical vehicles. In response to this, electric motors have received a lot of attention from manufacturers due to their critical role in the green revolution as a key component for the construction of electric vehicles [1]. In order to meet the uprising demand for reliable electric motors with specific tolerances, a manufacturing process with strict process control and high flexibility has to be achieved [2]. Manufacturing tolerances in process (e.g. during winding and terminations) have been proven to have an influence on the operating behaviour of electrical machines [3]. The commonly occurring faults such as overheating, insulation breakdown, bearing failure that occur during operation could be attributed to a lack of process control during manufacturing [2].

Currently, these faults are identified at the end of the line tests consisting of an offline inspection that uses statistical process control to encounter and manage potential defects [3]. In order to avoid accumulation of defects during the production chain, it is desirable to identify and react to detected defects early in the process without having to wait until 
the final stage of the manufacturing chain. Also, the End of Line (EoL) tests tend to be time-consuming and the costly.

In electrical machine manufacturing, coil winding is a key manufacturing step involving enamelled copper wire as a key component. Enamelled copper wire is a deformable material and a variation in the diameter of the wire alters its physical and the electrical properties leading to a generation of geometric and electric faults. [2]. A variation in physical or electrical properties of the wire can have a downstream effects in future manufacturing steps such as impregnation or joining (crimping) due to gaps or air pockets. In order to avoid accumulation of faults or defects during the production chain, it is desirable to identify and react to detected defects early in the process without having to wait until the final stage of the manufacturing chain. This can be achieved by identifying how critical process parameters and the interdependencies between them influence the origin or occurrence of defects [4]. This poses a challenge in electrical machine manufacturing because of the complexity involved in various manufacturing steps involving deformable material, an example is coil winding. Previous research has reported analysis of individual manufacturing steps using various modelling techniques, thus leaving a gap in understanding of interdependencies between process parameters from various steps on origin or occurrence of defects.

This paper proposes a computational framework to model interdependencies in a complex electrical machine manufacturing process, where time dependency is a vital aspect while dealing with process parameters that affect the properties of deformable components during the manufacturing process. A Discrete Event Simulation model simulated the behaviour of the wire during the process of coil-winding. Results demonstrated that input parameters such as wire tension and winding speed influence physical and electrical properties of the coil (enamelled copper wire) leading to generation of defects in the final product. In an industrial setting, when the current state/parameters from a live shop floor are passed in the model, it should be able to project the state of the coil and determine if or where the defects are likely to occur

\section{Problem definition}

In electrical machine manufacturing, the process of coil winding is one of the most important and complex processes and as a result has one of the highest influences on the generation of faults. Coil winding impacts more than 10 EoL tests (e.g. tests for electrical resistance, noise, vibration and cogging torque etc. [5]).

According to Mayr [6], faults generated during winding can be divided into two main categories: geometrical and electrical. The geometrical faults tend to be defects that are produced during winding due to deviations in the winding structure scheme or the bobbin's geometry that creates an abnormal layer structure resulting in faults such as double winding, gap, loose wire, and flange winding (as shown in Fig 1. a). The electrical faults occur due to the deformability of the copper wire. Any change in cross section of the wire will result in a variation in its electrical properties [3, 7]. Unlike many other materials, Copper does not have a fixed point for the transition from elastic to plastic deformation. A plastic deformation leads to a change in cross section of the wire and an increased winding resistance [3]. The ability to model these changes and predict their outcomes is therefore important when it comes to process monitoring within EM manufacture. 


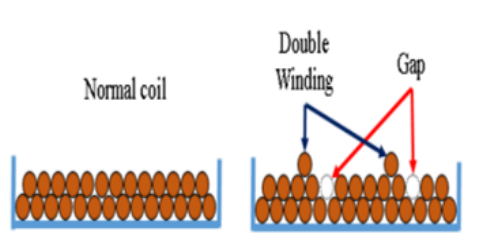

(a)

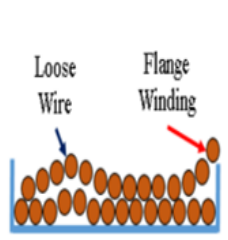

coo 00000000

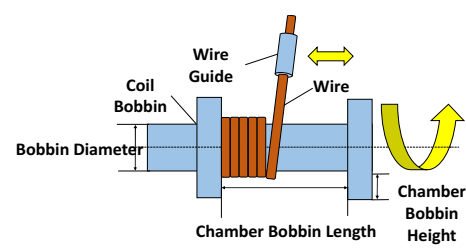

(b)

Figure 1. a) Main layer structure faults detected in coils [3], b) A simple representation of a linear winding process

\section{Methodology for development of the simulation model}

\subsection{Identification of an error-prone manufacturing process}

The coil winding was identified as an error-prone process because it involves the use of a deformable material (enamelled copper wire). A typical representation of a linear winding is shown in Figure 1 (b). A detailed overview on geometrical and electrical faults that can occur during coil winding has been provided in [2, 3]. Utilising the cause-effect analysis from reference $[2,3]$, key input parameters for the coil-winding process and the main faults/defects occurring during the process were identified.

\subsection{Development of a DES Model for the coil winding process}

A Discrete event simulation (DES) model was developed using the software Witness Horizon (provided by the Lanner group). DES was suitable for this study because it allowed the system under analysis to be described as a sequence of operations focusing on the processes in a system at a medium level of abstraction. The models was based on data gathered from the shop floor and the information obtained from industry interviews.

\subsubsection{Identification of first parameters}

The parameters for the simulation model has to be established before writing the logic of the model. Based on the matrix created by Sell-Le Blanc et al. [3] the influence that input parameters have on the creation of faults has been outlined, as shown in Fig 2. The columns present the input parameters to be used in the model. The rows list the possible faults that can occur during the winding process. The colour coding in Fig 2 demonstrates the influence of a process parameter (in columns) on generation of a type of fault (in rows). The key input parameters that were included in the model were wire tension, winding speed and caster angle of the wire (as listed in Fig. 4(a)).

\subsubsection{The logic and rules}

The DES model represented linear winding process for noncircular orthocyclic coils. The output wound coil comprised of 15 layers each with 20 turns. During each turn, a local resistance value for that turn was calculated depending the various input parameters such as wire tension and winding speed. The rules that determined the generation of a particular fault with respect to a process parameter are listed in Fig 3. 


\begin{tabular}{|c|c|c|c|c|c|c|c|c|c|c|c|c|c|c|}
\hline \multirow[b]{3}{*}{ Winding fault } & \multicolumn{7}{|c|}{ Process } & \multicolumn{5}{|c|}{ Wire } & \multirow{2}{*}{\multicolumn{2}{|c|}{$\begin{array}{c}\text { Coil bobbin } \\
\text { Geometry }\end{array}$}} \\
\hline & \multicolumn{5}{|c|}{ Machine } & \multicolumn{2}{|c|}{ Wire } & \multicolumn{3}{|c|}{ Geometry } & \multicolumn{2}{|c|}{ Mechanical } & & \\
\hline & $\begin{array}{c}\text { Caster } \\
\text { angle }\end{array}$ & $\begin{array}{c}\text { Wire feeding } \\
\text { speed }\end{array}$ & $\begin{array}{l}\text { Wire feed } \\
\text { rate }\end{array}$ & Exit angle & $\begin{array}{l}\text { Winding } \\
\text { speed }\end{array}$ & $\begin{array}{l}\text { Wire } \\
\text { tension } \\
\text { (global) }\end{array}$ & $\begin{array}{c}\text { Wire } \\
\text { tension } \\
\text { (local) }\end{array}$ & $\begin{array}{c}\text { Outer } \\
\text { wire } \\
\text { gauge }\end{array}$ & $\begin{array}{c}\text { Inner } \\
\text { wire } \\
\text { gauge }\end{array}$ & $\begin{array}{c}\text { Plastic } \\
\text { deformation }\end{array}$ & $\begin{array}{c}\text { Failure } \\
\text { strain }\end{array}$ & $\begin{array}{l}\text { Tensile } \\
\text { strength }\end{array}$ & Length & Width \\
\hline Faulty electric resistance & M & $M$ & M & H & $\mathrm{H}$ & H & H & $\mathrm{H}$ & $\mathrm{H}$ & H & H & H & $\mathrm{L}$ & $\mathrm{H}$ \\
\hline Short dircuit & M & M & $\mathrm{M}$ & H & $\mathrm{H}$ & H & H & M & M & H & H & H & M & $\mathrm{H}$ \\
\hline Reduce High Voltage strength & $M$ & $\mathrm{M}$ & $M$ & H & $\mathrm{H}$ & $H$ & $\mathrm{H}$ & $\mathrm{M}$ & M & H & $\mathrm{H}$ & $\mathrm{H}$ & M & $\mathrm{H}$ \\
\hline Wire Damage & $M$ & $\mathrm{M}$ & $M$ & $\mathrm{H}$ & $\mathrm{H}$ & $\mathrm{H}$ & H & M & $M$ & H & $\mathrm{H}$ & $\mathrm{H}$ & M & H \\
\hline Wire fracture & M & $\mathrm{M}$ & $\mathrm{M}$ & $\mathrm{H}$ & $\mathrm{H}$ & H & $\mathrm{H}$ & M & M & $\mathrm{H}$ & $\mathrm{H}$ & H & M & $\mathrm{H}$ \\
\hline Winding scheme (wild) & H & $\mathrm{H}$ & H & H & $\mathrm{H}$ & H & H & $\mathrm{H}$ & $\mathrm{H}$ & H & H & H & M & $\mathrm{H}$ \\
\hline Loose winding & H & $\mathrm{M}$ & $\mathrm{H}$ & H & $\mathrm{H}$ & $H$ & H & H & $\mathrm{H}$ & $\mathrm{M}$ & H & H & $\mathrm{M}$ & $\mathrm{M}$ \\
\hline Concision of winding & M & M & M & $\mathrm{H}$ & $\mathrm{H}$ & $\mathrm{H}$ & $\mathrm{H}$ & M & M & H & H & $\mathrm{H}$ & M & M \\
\hline Defective outer diameter & $\mathrm{H}$ & $\mathrm{H}$ & $\mathrm{H}$ & $\mathrm{H}$ & $\mathrm{H}$ & $\mathrm{H}$ & $\mathrm{H}$ & $\mathrm{H}$ & $\mathrm{H}$ & $\mathrm{H}$ & $\mathrm{H}$ & H & M & $\mathrm{H}$ \\
\hline Defective inner diameter & $\mathrm{L}$ & $\mathrm{L}$ & $\mathrm{L}$ & H & $\mathrm{H}$ & $\mathrm{H}$ & $\mathrm{H}$ & $\mathrm{M}$ & M & $\mathrm{H}$ & $\mathrm{H}$ & $\mathrm{H}$ & H & $\mathrm{H}$ \\
\hline
\end{tabular}

Defective inner diameter

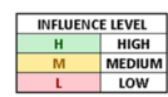

Figure 2. Main winding faults and influencing parameters during linear winding adapted from [3]. The influence level informs the impact of a particular parameter on the generation of faults.

\begin{tabular}{|c|c|c|c|}
\hline & Input parameters & Interdependencies & Faults \\
\hline \multirow{5}{*}{ 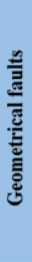 } & $\begin{array}{l}\text { Winding Speed, Wire gauge, Caster angle, Free length wire, } \\
\text { Tensile strength, Spring-back behavior, Turning point }\end{array}$ & $\begin{array}{l}\text { Variations in the diameter of the wire will affeet the easter angle, having a smaller diameter } \\
\text { than requested will produce negative easter angle resulting in the spread of windings. }\end{array}$ & Gap \\
\hline & $\begin{array}{l}\text { Winding Speed, Wire gauge, Caster angle, Free length wire, } \\
\text { Tensile strength, Spring-back behavior }\end{array}$ & $\begin{array}{l}\text { Variations in the diameter of the wire will affeet the easter angle, having a larger diameter than } \\
\text { requested will eause that the maximum easter angle is reach leading to slower speeds for the } \\
\text { wire guide resulting in wires bracing against each other. }\end{array}$ & Double Winding \\
\hline & $\begin{array}{l}\text { Fill factor, Bobbin width, Strueture of winding surface, Aspeet } \\
\text { ratio, Winding Speed, Wire gauge, Caster angle, Free length wire, } \\
\text { Tensile strength, Spring-back behavior, Turning point }\end{array}$ & $\begin{array}{l}\text { Having a Fill factor between } 65.75 \% \text { is determine as a wild winding structure. This strueture } \\
\text { eauses that wires to lie uneven ontop of each other, leading to wires falling into eavities ereated } \\
\text { on the lower layers. }\end{array}$ & Cross Over \\
\hline & $\begin{array}{l}\text { Winding Speed,Caster angle, Wire feed rate, Free length wire, } \\
\text { Wire gauge, Tensile strength, Spring-back behavior, Turning point }\end{array}$ & $\begin{array}{l}\text { A sudden increase in the speed of wire feed will produee a greater uncertainty in the positioning } \\
\text { of the wire leading to an inaceurate reversal span of the axis when ehanging direetions, } \\
\text { therefore missing the turning points and laying the wire on top of the flange. }\end{array}$ & Flange Winding \\
\hline & $\begin{array}{l}\text { Winding Speed, Caster Angle, Tensile strength, Free length wire, } \\
\text { Wire feed, Spring-back behavior, Wire gauge and Initial tension } \\
\text { before the wire break, Spring-back behavior }\end{array}$ & $\begin{array}{l}\text { Having a low tensile force from the wire break and a declining wire guide motion affects the } \\
\text { winding strueture with the ereations of loose winding or loops. }\end{array}$ & Loose Wire \\
\hline \multirow{3}{*}{ 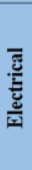 } & $\begin{array}{l}\text { Winding Speed, Exit Angle, Wire Tension \& Gauge, Free wire } \\
\text { length, Tensile Strength, Wire hardness, Bending Radii }\end{array}$ & $\begin{array}{l}\text { High winding speeds leads to variations in the tensile strength applied to the wire, reducing the } \\
\text { eross seetional area of the wire. Leading to abnormalities in the electrical properties of the wire. }\end{array}$ & $\begin{array}{l}\text { High Electrical } \\
\text { Resistance and } \\
\text { Inductance }\end{array}$ \\
\hline & $\begin{array}{l}\text { Strueture of winding surface, Exit angle, Wire Tension (bending } \\
\text { and tensile stress), Friction, Lubrication, Insulation thickness, } \\
\text { winding speed, free wire length, wire hardness, wire gauge, }\end{array}$ & $\begin{array}{l}\text { Damaged to the wire due to blurs in the bobbin's surface, a deteriorated exit angle in the wire } \\
\text { guide, lack of lubrication results in too much friction that damages the insulation layer and } \\
\text { eventually produces tearing of the wire affecting its electrie strength with partial discharges. }\end{array}$ & $\begin{array}{l}\text { Reduce High-Voltage } \\
\text { Strength }\end{array}$ \\
\hline & $\begin{array}{l}\text { Insulation thickness, Wire Tensile force, Exit angle, Friction, } \\
\text { Lubrication, Strueture of winding surface }\end{array}$ & $\begin{array}{l}\text { Having a damage wire where the insulation has been tom and the copper wire has been } \\
\text { exposed in consecutive turns or layers will make the current travel through an unintended path } \\
\text { with low electrical resistance eausing the temperature too inerease. }\end{array}$ & Short eireuit \\
\hline
\end{tabular}

Figure 3. Logic that the DES model follows according to literature [8][9]

\section{Results and discussion}

\subsection{Electrical resistance and wire tension}

The model calculated the electrical resistance $(\mathrm{R})$ of the Copper wire for individual turns in each layer of the winding, using Eq.1. A deviation from set values of critical input parameters such as wire tension or winding speed (Fig 4 (a)) resulted in a change in electrical resistance that was calculated as VarER for every turn in the winding, Eq. 2.

$$
\begin{gathered}
R=\rho x \frac{l}{A}=\rho x \frac{4 x l}{\pi x d^{2}} \\
\operatorname{VarER}=A b s\left(\frac{\text { ERnormal-ERnew }}{\text { ERnormal }}\right) \times 100
\end{gathered}
$$

Equation 1 depicts that tapering or reduced cross section (d) of the wire will lead to an increase in resistance (R). Equation 2 shows the calculation for variation in resistance (VarER). The model recorded variation in resistance for every turn allowing locating areas of high electrical resistance in the coil winding and marking them as regions of interest for future reference in downstream inspection steps, as shown in Fig 5 (b). 


\begin{tabular}{|c|c|l|}
\hline \multicolumn{3}{|c|}{ Input Parameters } \\
\hline \hline Wire Diameter & $\mathbf{1}$ & $\mathbf{m m}$ \\
\hline Wire Feed & 3.33 & $\mathrm{~mm} / \mathrm{s}$ \\
\hline Number of turns & 20 & \\
\hline Number of layers & 15 & \\
\hline Bobbin Width & 30 & $\mathrm{~mm}$ \\
\hline Bobbin Heigth & 20 & $\mathrm{~mm}$ \\
\hline Bobbin Radius & 15 & $\mathrm{~mm}$ \\
\hline Winding Speed & 200 & RPM \\
\hline Tensile strength & $\mathbf{4 0}$ & Newtons \\
\hline
\end{tabular}

(a)

\begin{tabular}{|c|c|c|c|}
\hline $\begin{array}{c}\text { Wire gauge } \\
(\mathrm{mm})\end{array}$ & $\begin{array}{c}\text { Wire Guide Speed } \\
(\mathrm{mm} / \mathrm{s})\end{array}$ & $\begin{array}{c}\text { Maximum Caster } \\
\text { Angle }\left({ }^{\circ}\right)\end{array}$ & $\begin{array}{c}\text { Safety Caster } \\
\text { Angle }\left({ }^{\circ}\right)\end{array}$ \\
\hline 0.90 & 35.8 & 12.38698589 & 4.954794357 \\
\hline 0.92 & 35.3 & 12.46789896 & 4.987159584 \\
\hline 0.94 & 34.8 & 12.54707183 & 5.018828732 \\
\hline 0.96 & 34.3 & 12.62457778 & 5.04983111 \\
\hline 0.98 & 33.8 & 12.70048555 & 5.080194218 \\
\hline 1.00 & 33.3 & 12.77485972 & 5.109943889 \\
\hline 1.02 & 32.8 & 12.84776104 & 5.139104417 \\
\hline 1.04 & 32.3 & 12.91924672 & 5.167698686 \\
\hline
\end{tabular}

(b)

Figure 4 (a) Input parameters for DES model (b) Interdependency between the size of the wire gauge, the wire guide speed and the caster angle.

In the model, for a wire gauge of $1.18 \mathrm{~mm}$ (yield limit of $61.75 \mathrm{~N}$ ), an optimal tension value of $40 \mathrm{~N}$ was set with a winding speed of $100 \mathrm{rpm}$. As long as the applied wire tension in the wire was less than the yield point of the wire, the elastic deformation in the wire will not create a permanent change in electrical resistance of wire in that region. However, due to an increase in the winding speed, when the wire tension increased beyond the yield limit of the wire, plastic deformation occurs that reduces the wire gauge/cross section resulting in an increased electrical resistance of the wire in that region. It was found that geometric faults in the winding, such as gap, could also occur due to reduced wire gauge. Fig. 5 (a) shows the results from DES model depicting a change in electrical resistance of the wire with respect to the applied wire tension. It was observed that when the winding speed increased above $300 \mathrm{rpm}$, the applied tension in the wire increased beyond the yield limit of the wire $(61.75 \mathrm{~N})$, leading to a plastic deformation in the wire and a permanent reduction in wire gauge. On the other hand, a decrease in applied wire tension resulted in loose wires or loops in the winding.

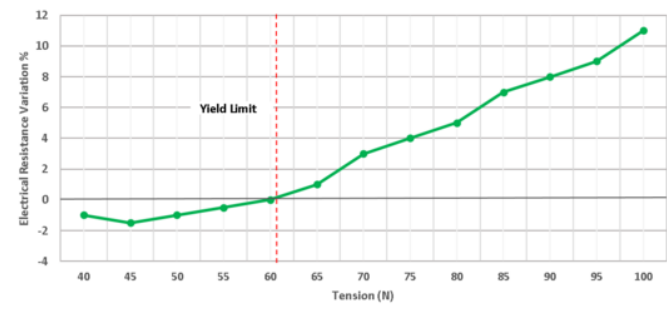

(a)

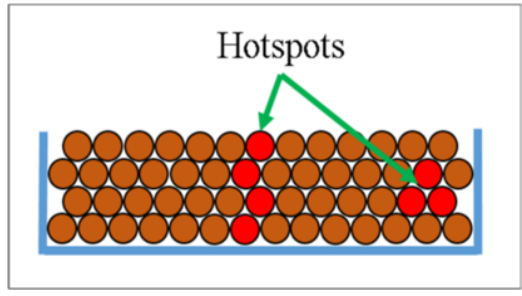

(b)

Figure 5 a) Graph showing variation in electrical resistance with respect to tension in the wire, the orange dashed line shows yield point of the wire. (b) Representation hotspots in different winding layers (in red)

Another feature included in the DES model was cumulated error in winding. This feature accumulates the total error during winding allowing manufacturers to determine when the winding process in a particular layer is within the safety limits and alerting when it has gone above a designated threshold and will create repercussions in proceeding layers. If fed with real data from a live shop floor, this feature of cumulated error allows the user to make decisions on whether to proceed or reject the coil before moving to the next manufacturing step. 


\subsection{Wire gauge, wire guide and caster angle}

The results obtained from the DES model highlighted that several factors influence the creation of geometrical and electrical faults during winding. The input parameters that had the highest influence on the creation of faults during winding were wire diameter (gauge), winding speed of the bobbing and applied tension in the wire. Other input parameters that were included in the DES model were free wire length, exit angle and feed rate (Fig. 4 (a). It was revealed that the dimensions of enamelled copper wire had a significant impact on the output winding quality. There are two possible sources for a variation in the wire gauge, when tolerances during manufacturing of the wire are inappropriate or when inappropriate tensile stress is applied during winding. The DES model showed that when there is a variation in the wire gauge, the speed of the wire guide also changed. This interdependency is shown in Fig 6. a, where the speed is influenced by the weight of the wire. Commonly, this occurs because a smaller diameter makes the wire lighter allowing the guide to move faster than usual. Besides, if the wire gauge is larger than expected the extra weight will make the wire guide move slower hence affecting the caster angle. This affects the winding geometry creating different contours such as bulgy, convex and concave winding leading to a reduction of the fill factor.

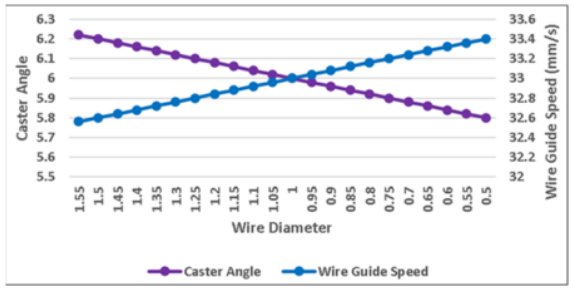

(a)

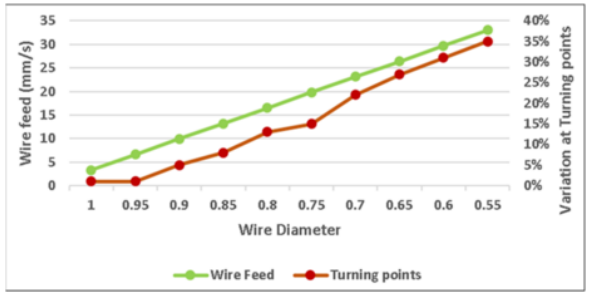

(b)

Figure 6 (a) Variation in winding speed and caster angle with respect to the diameter of the wire. (b) Relationship between wire diameter, wire feed rate and variation of wire guide at turning points.

The caster angle is influenced directly by the wire guide speed. When the wire guide moves slower than usual, it gradually reduces the caster angle until the point the angle becomes negative. A negative caster angle creates gaps in the winding structure, which reduces the fill factor of the bobbin from $90.7 \%$ to a range between $65-75 \%$. On the other hand, if the wire guide moves faster than required then it will cause the caster angle to increase leading to generation of a double winding fault. Using the method proposed by [8] the DES model calculates the maximum caster angle and the safety caster angle, the results are shown in Fig. 6 (a). Therefore, if a sudden change in speed occurs on the wire guide due to continuous change in the diameter of the wire, the wire feed increases and it will naturally not be able to reach the established turning points accordingly, as shown in Fig 6. (b). This occurs when the wire feed speed does not correspond to the winding location producing an abnormal acceleration effect. Fig. 6 (b) shows that for wires of smaller diameter, the wire guide will be faster and therefore higher the variation when trying to reach the turning points. 


\section{Conclusions and future work}

The manufacturing of electrical machines is a complex process involving deformable material. In order to avoid accumulation of defects during the production chain, it is desirable to identify and react to detected defects early in the process. In order to achieve this goal, critical process parameters and their interdependencies on the origin or occurrence of defects needs to be fully understood.

This paper proposed a computational framework to model interdependencies in a complex electrical machine manufacturing process, where time dependency is a vital aspect while dealing with process parameters affecting properties of deformable copper wire during the manufacturing process. A Discrete Event Simulation model simulated the behaviour of the wire during the process of coil-winding. Results demonstrated that input parameters such as wire tension and winding speed influence physical and electrical properties of the wire leading to a generation of defects in the final product. The DES model could locate the specific turns and layers in the coil where faults had occurred indicating a region of hotspot for inspection.

The future work will be to combine the developed framework with a Neural Network (NN) to predict the current state of a component and reduce the time required to perform online quality control tests by identifying the effects that interdependencies have in the process. This approach is suggested by training a NN to learn how interdependencies influence the quality outcomes (defects) of a process that contains multiple steps and minimize the effects as much as possible by identifying the optimal settings for the machine. The model also allows possible training data to be generated from the model that mimics real-life process variation and links to failure.

\section{Acknowledgements}

This project was supported by the Engineering and Physical Sciences Research Council of the UK through the Future Electrical Machines Manufacturing Hub (EP/S018034/1). The authors would like to thank Airbus and the Royal Academy of Engineering under the Research Chairs and Senior Research Fellowships scheme. The co-author IOEO would like to thank the Mexican National Council of Science and Technology (CONACYT) for supporting his $\mathrm{PhD}$ program.

\section{References}

[1] A. Mayr et al., "Electric Motor Production 4.0 - Application Potentials of Industry 4.0 Technologies in the Manufacturing of Electric Motors," 2018 8th Int. Electr. Drives Prod. Conf. EDPC 2018 - Proc., 2019, doi: 10.1109/EDPC.2018.8658294.

[2] F. S. Blanc, Handbook of Coil Winding. 2018.

[3] J. Sell-Le Blanc, F., Fleischer, J., Sautter, S., Delzs, T., \& Hagedorn, "Fault Analysis of Linear Winding Processes for Noncircular Orthocyclic Coils," 2014.

[4] A. Albers, T. Stürmlinger, C. Mandel, J. Wang, M. B. de Frutos, and M. Behrendt, "Identification of potentials in the context of design for industry 4.0 and modelling of interdependencies between product and production processes," Procedia CIRP, vol. 84, pp. 100-105, 2019, doi: 10.1016/j.procir.2019.04.298.

[5] D. Tiwari, M. Farnsworth , G.W. Jewell, A. Tiwari, "In-process monitoring in electrical machine manufacturing - A review of state of the art and future directions," J. Eng. Manuf., 2021, doi:10.1177/09544054211016675

[6] A. Mayr, D. Kißkalt, A. Lomakin, K. Graichen, and J. Franke, "Towards an intelligent linear winding process through sensor integration and machine learning techniques," Procedia CIRP, vol. 96, pp. 80-85, 2020, doi: 10.1016/j.procir.2021.01.056. 
[7] F. S. Le Blanc, J. Fleischer, M. Schmitt, M. Unger, and J. Hagedorn, "Analysis of wire tension control principles for highly dynamic applications in coil winding: Investigation of new tension control devices for noncicurlar orthocyclic coils," 2015 5th Int. Conf. Electr. Drives Prod. EDPC 2015 - Proc., 2015, doi: 10.1109/EDPC.2015.7323202.

[8] F. Erlangen and A. Dobroschke, Fertigungstechnik - Erlangen. .

[9] K. Wolf, "Verbesserte Prozeßführung und Prozeßplannung zur Leistungs- und Qualitätssteigerung beim Spulenwickeln,” Fert. Erlangen, p. 184, 1997. 